\title{
Improvement of perinatal and newborn care in rural Pakistan through community-based strategies: a cluster-randomised effectiveness trial
}

\author{
Zulfiqar A Bhutta, Sajid Soofi, Simon Cousens, Shah Mohammad, Zahid A Memon, Imran Ali, Asher Feroze, Farrukh Raza, Amanullah Khan, \\ Steve Wall, Jose Martines
}

\section{Summary}

Background Newborn deaths account for $57 \%$ of deaths in children younger than 5 years in Pakistan. Although a large programme of trained lady health workers (LHWs) exists, the effectiveness of this training on newborn outcomes has not been studied. We aimed to evaluate the effectiveness of a community-based intervention package, principally delivered through LHWs working with traditional birth attendants and community health committees, for reduction of perinatal and neonatal mortality in a rural district of Pakistan.

Methods We undertook a cluster randomised trial between February, 2006, and March, 2008, in Hala and Matiari subdistricts, Pakistan. Catchment areas of primary care facilities and all affiliated LHWs were used to define clusters, which were allocated to intervention and control groups by restricted, stratified randomisation. The intervention package delivered by LHWs through group sessions consisted of promotion of antenatal care and maternal health education, use of clean delivery kits, facility births, immediate newborn care, identification of danger signs, and promotion of careseeking; control clusters received routine care. Independent data collectors undertook quarterly household surveillance to capture data for births, deaths, and household practices related to maternal and newborn care. Data collectors were masked to cluster allocation; those analysing data were not. The primary outcome was perinatal and allcause neonatal mortality. Analysis was by intention to treat. This trial is registered, ISRCTN16247511.

Findings 16 clusters were assigned to intervention (23353 households, 12391 total births) and control groups (23768 households, 11443 total births). LHWs in the intervention clusters were able to undertake 4428 (63\%) of 7084 planned group sessions, but were only able to visit 2943 neonates (24\%) of a total 12028 livebirths in their catchment villages. Stillbirths were reduced in intervention clusters (39.1 stillbirths per 1000 total births) compared with control $(48.7$ per 1000 ; risk ratio $[R R] 0.79,95 \%$ CI $0.68-0.92 ; p=0.006)$. The neonatal mortality rate was 43.0 deaths per 1000 livebirths in intervention clusters compared with 49.1 per 1000 in control groups (RR 0.85 , $0 \cdot 76-0 \cdot 96 ; \mathrm{p}=0 \cdot 02)$.

Interpretation Our results support the scale-up of preventive and promotive maternal and newborn interventions through community health workers and emphasise the need for attention to issues of programme management and coverage for such initiatives to achieve maximum potential.

Lancet 2011; 377: 403-12 Published Online January 15, 2011 DOI:10.1016/S01406736(10)62274-X See Comment page 361 Division of Women and Child Health, Aga Khan University, Karachi, Pakistan (Prof Z A Bhutta PhD, S Soofi FCPS,

S Mohammad MPH,

Z A Memon MSc, I Ali MSc, A Feroze MSc, F Raza MPH); London School of Hygiene and Tropical Medicine, London, UK (S Cousens DipMathStats); Saving Newborn Lives, Save the Children USA, Washington, DC, USA (A Khan MPH, SWall MD); and Department of Child and Adolescent Health, WHO, Geneva, Switzerland (J Martines PhD)

Correspondence to: Prof Zulfiqar A Bhutta, Husein Lalji Dewraj Professor and Founding Chair, Division of Women and Child Health, Aga Khan University, Karachi 74800, Pakistan zulfiqar.bhutta@aku.edu

Funding WHO; Saving Newborn Lives Program of Save the Children USA, funded by the Bill \& Melinda Gates Foundation.

\section{Introduction}

Although there has been some reduction in global child mortality, ${ }^{1}$ there is little evidence to suggest that newborn deaths have reduced significantly from the estimated yearly figure of 4 million deaths in 2000. ${ }^{2}$ Pakistan has one of the highest rates of mortality in children younger than 5 years in south Asia (94 deaths per 1000 livebirths), and many $(57 \%)$ of these deaths occur in the newborn period, most in the first few days after delivery. ${ }^{3}$ There are significant urban-rural differentials in neonatal mortality rates (48 newborn deaths per 1000 livebirths in urban areas vs 55 per 1000 in rural areas) and overall $65 \%$ of births take place at home (43\% urban vs $74 \%$ rural). ${ }^{3}$ More than half $(52 \%)$ of these births are in the hands of traditional birth attendants (Dais), ${ }^{4,5}$ who are generally untrained and who charge for their services.
To help to strengthen primary care and preventive services, the government of Pakistan introduced the National Program for Family Planning and Primary Health Care, commonly called the lady health workers (LHW) programme, in $1994 .{ }^{6}$ LHWs are mostly young women, resident in the local communities, with at least 8 years of formal schooling, who are trained for 15 months to deliver care in community settings either through home visits or from their residences, known as health homes. Each LHW is responsible for a population of about 1000-1500 and provides antenatal care, contraceptive advice, growth monitoring, and immunisation services. ' The emphasis in the existing curriculum is on recognition and referral rather than home-based management of common neonatal problems, and two recent evaluations have concluded 
Panel 1: Changes made to the training curriculum for lady health workers, community engagement, data collection, and surveillance on the basis of the pilot phase $\mathrm{e}^{16}$

\section{Training in preventive newborn care}

An augmented training package was developed for intervention lady health workers (LHWs) in consultation with the LHW programme (table 1) and implemented by regular LHW programme supervisors and trainers. The standard LHW training took place during a period of 15 months, including 3 months of didactic training and monthly refresher sessions of 1 day each. The study intervention package only added an extra 6 days to LHW training. This extra training encouraged LHWs to identify all pregnant women in their area, provide basic antenatal care (including rest and nutrition counselling, screening for common illnesses, iron folate and tetanus toxoid administration) and work with traditional birth attendants (Dais) to identify births. LHWs were trained in mouth-to-mouth resuscitation, but no resuscitation equipment or injectable antibiotics were provided to them. Clean delivery kits were provided to LHWs in both intervention and control clusters and were also available for purchase in local pharmacies. LHWs were encouraged to visit mothers twice during pregnancy and within $24 \mathrm{~h}$ of birth. Additionally, visits were encouraged on days $3,7,14$, and 28 after birth. LHWs were reimbursed for any additional travel costs arising from the intervention and training, but did not receive any additional salary or other financial motivation.

\section{Dai training for basic newborn care}

With the assistance of Directorate of Health staff, we developed a 3-day training programme for Dais in basic newborn care including basic resuscitation (through skin rubbing, sole flicking, and immediate newborn care). No remuneration, commodities, or monetary incentives were provided to the Dais for these training sessions apart from transportation to basic health units and meals or refreshments. Attendance was entirely voluntary (webappendix p 2). Dais were informed about these training sessions through the LHWs and community health committees (CHCs) and were also encouraged to attend the LHW-led community education sessions. No training sessions were held in the control clusters.

\section{Community organisation, mobilisation, and group education sessions}

Three community mobilisers from Aga Khan University (Karachi, Pakistan) assisted the LHWs in identifying community volunteers in intervention communities. Community volunteers were encouraged to form CHCs in liaison with LHWs with the aim of promoting maternal and newborn care in their villages. In addition to advocacy work with community elders and local political leaders, the CHCs were encouraged to organise an emergency transport fund and use of vehicles using local resources. The CHCs facilitated the LHWs in accessing women and in conducting group education sessions in the intervention villages. These sessions, attended by women of reproductive age, adolescent girls, and older women, were held on a quarterly basis in a local household. The LHWs, often assisted by Dais, facilitated these group sessions using standard materials and flip charts developed for this purpose. Additionally, a two-part video docudrama on pregnancy and newborn care was produced and made available to intervention cluster LHWs for use in group sessions using available village resources (a home television and video cassette player). These sessions and related materials were in the local language (Sindhi) and focused on key knowledge and behaviours listed in table 1.

See Online for webappendix that they do provide reasonable primary care promotive and preventive services. ${ }^{8,9}$

The potential of community-based interventions to reduce newborn morbidity and mortality is well recognised. ${ }^{10,11}$ Such interventions include community health workers (CHWs) delivering preventive and therapeutic interventions such as antibiotics at home, ${ }^{12,13}$ community mobilisation through women's support groups $^{14,15}$ or community mobilisers working through individual and group sessions, ${ }^{16}$ and community-based interventions delivered through non-governmental organisations $^{17}$ or community volunteers. ${ }^{18}$ Common features of these interventions include civil society engagement, flexibility of approaches, community volunteers, social mobilisers, or CHWs dedicated to the designated tasks through home visits or group sessions. However, despite the success of these projects (largely undertaken as efficacy trials), translation of these interventions into packages of care and complex interventions that can be delivered within public health systems at scale remains a major challenge. ${ }^{19}$ Most of these studies were fairly small and none principally used the public sector, making translation of this evidence to public health systems difficult.

We undertook the first effectiveness trial of a package of preventive maternal and newborn care strategies in rural Pakistan, delivered through public sector LHWs in collaboration with voluntary community health committees (CHCs) and Dais. We have previously reported findings from the development and pilot testing phase of the project, ${ }^{16}$ which showed the feasibility of delivering the package of care through government sector LHWs.

\section{Methods \\ Study design}

We undertook a cluster randomised trial in rural Sindh in southern Pakistan. The Hala and Matiari subdistricts (hereafter called Hala) are located $250 \mathrm{~km}$ north of Karachi and include two towns and 1400 villages, with an official population of 0.6 million. We undertook a survey of all facilities (22 basic health units [BHUs], two rural health centres [RHCs] of which one was upgraded to a referral hospital status in 2006, and a district referral hospital) and LHWs in the area. 437 LHWs were available in the district, of 500 approved positions. The distribution of these LHWs was variable, with several villages covered by non-residential LHWs who lived elsewhere and commuted to work. There were two district referral hospitals located in Hala town and Matiari, with one paediatrician, two obstetricians, and several medical officers. Several midwives were available in the area, with most working within the private sector. Webappendix $\mathrm{p} 1$ shows further details of the study area and local health systems.

We developed an intervention package for promotive and preventive newborn care in collaboration with the Directorate of Health, Government of Sindh, which has been described previously. ${ }^{16}$ The intervention consisted of training of LHWs and Dais and promotion of liaison between them, together with facilitation of the creation of voluntary CHCs to promote maternal and newborn care in their villages. The intervention package was pilot tested in four clusters (with four control clusters) in the district from 2003 to 2005 to refine methods and to assess acceptability by the population. Some modifications of the LHW training curriculum, 


\begin{tabular}{|c|c|c|}
\hline & $\begin{array}{l}\text { Control } \\
\text { clusters }\end{array}$ & $\begin{array}{l}\text { Intervention } \\
\text { clusters }\end{array}$ \\
\hline \multicolumn{3}{|l|}{ Community health committees } \\
\hline $\begin{array}{l}\text { Creation of volunteer-based village } \\
\text { health committees }\end{array}$ & $\mathrm{x}$ & $\sqrt{ }$ \\
\hline \multicolumn{3}{|c|}{ Traditional birth attendant (Dai) training and linkage } \\
\hline $\begin{array}{l}\text { Basic training and linkage of traditional } \\
\text { birth attendants with LHWs }\end{array}$ & $x$ & $\sqrt{ }$ \\
\hline \multicolumn{3}{|l|}{ LHW programme support and training } \\
\hline Promotion of antenatal care & $\sqrt{ }$ & $\sqrt{ }$ \\
\hline Iron folate use in pregnancy & $\sqrt{ }$ & $\sqrt{ }$ \\
\hline Immediate newborn care & $\sqrt{ }$ & $\sqrt{ }$ \\
\hline $\begin{array}{l}\text { Cord care (cleaning and avoidance of } \\
\text { traditional material application) }\end{array}$ & $\sqrt{ }$ & $\sqrt{ }$ \\
\hline Promotion of exclusive breastfeeding & $\sqrt{ }$ & $\sqrt{ }$ \\
\hline $\begin{array}{l}\text { Training in group counselling and } \\
\text { communication strategies }\end{array}$ & $x$ & $\sqrt{ }$ \\
\hline $\begin{array}{l}\text { Promotion of adequate maternal } \\
\text { nutrition and rest }\end{array}$ & $x$ & $\sqrt{ }$ \\
\hline $\begin{array}{l}\text { Promotion of early breastfeeding } \\
\text { (within the first hour) and colostrum } \\
\text { administration (avoidance of } \\
\text { prelacteal feeds) }\end{array}$ & $x$ & $\sqrt{ }$ \\
\hline $\begin{array}{l}\text { Promotion of delayed bathing and } \\
\text { improved home care for low } \\
\text { birthweight infants }\end{array}$ & $x$ & $\sqrt{ }$ \\
\hline $\begin{array}{l}\text { Recognition of sick newborn babies and } \\
\text { danger signs for referral }\end{array}$ & $x$ & $\sqrt{ }$ \\
\hline \multicolumn{3}{|c|}{$\begin{array}{l}X=\text { intervention not implemented. } \sqrt{ }=\text { intervention implemented. } L H W=\text { lady } \\
\text { health worker. }\end{array}$} \\
\hline
\end{tabular}

community engagement, data collection procedures, and surveillance were made on the basis of the pilot phase and are summarised in panel 1. In the control clusters, the LHW programme continued to function as usual and no additional attempt was made to link LHWs with the Dais or communities. They were, however, provided with regular refresher training according to the standard national LHW programme curriculum including monthly debriefing sessions in public sector health facilities. Table 1 shows details of the intervention package.

The Hala trial was approved by the ethics review committees of Aga Khan University (Karachi, Pakistan), London School of Hygiene and Tropical Medicine (London, UK), and WHO (Geneva, Switzerland).

\section{Randomisation and masking}

The key care provider within our intervention strategy was the LHW. Since LHWs are trained and supervised by staff in BHUs and RHCs and use only these facilities for regular replenishment of supplies and reporting, we used the catchment areas of individual functional primary care facilities (BHUs, RHCs) and all affiliated LHWs as units of randomisation or clusters for this trial. Altogether, 26 such clusters with

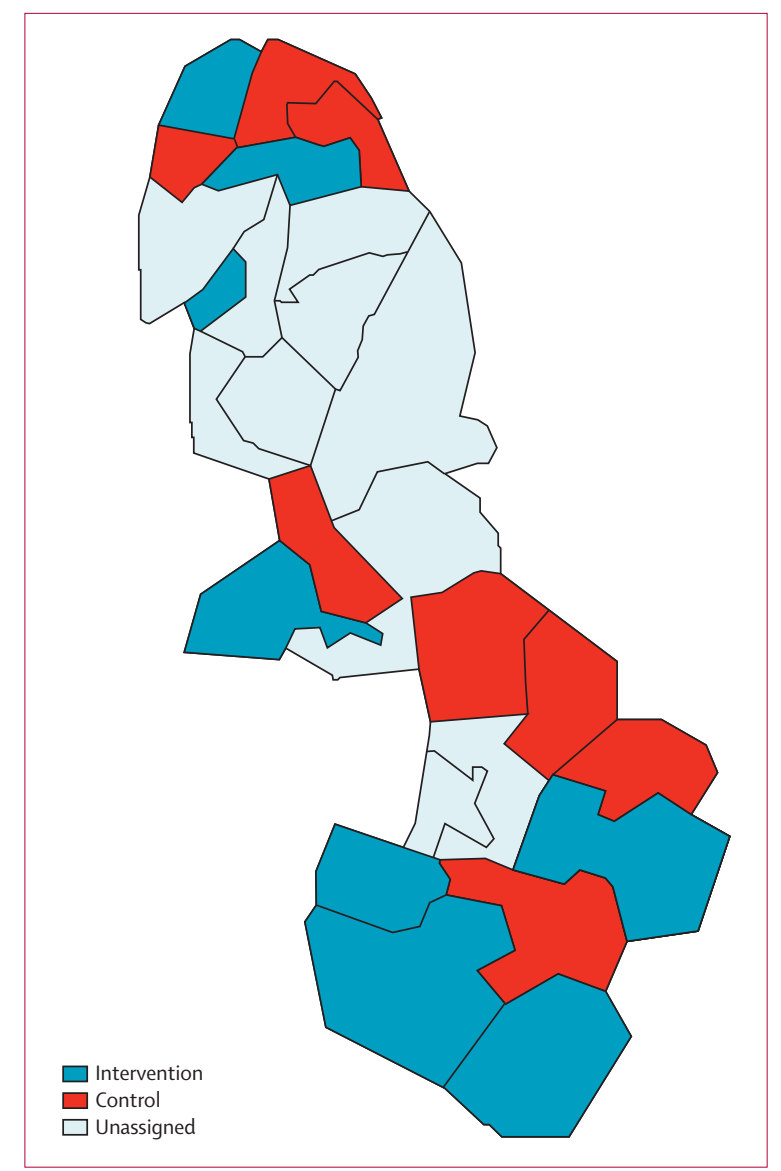

Figure 1: Cluster allocation in Hala and Matiari subdistricts, Pakistan

available LHWs were identified in the district, eight of which were involved in the pilot study. ${ }^{16}$ Two further clusters were excluded because they had very few LHWs and were largely in the riverine Katcha areas with poor access. The full trial was thus implemented in the remaining 16 clusters (figure 1) between February, 2006, and March, 2008. There were no exclusion criteria for LHWs, women, households, or clusters after randomisation.

To ensure reasonable balance between the two groups we used restricted, stratified randomisation to allocate clusters to the intervention and control groups. ${ }^{20}$ Three strata (consisting of two, six, and eight clusters) were identified on the basis of their size and the number of LHWs per 1000 population. We identified 126 random allocations that resulted in similar population sizes in the two groups (difference $<15000$ ), similar numbers of livebirths (difference <1000), similar neonatal mortality rates (NMRs; difference $<5$ deaths per 1000 livebirths), similar ratios of LHWs to population (difference $<0 \cdot 1$ per 1000), and similar proportions of women delivering in hospital (difference $<5 \%$ ). From this list of balanced allocations, we selected one scheme using a computergenerated random number. 


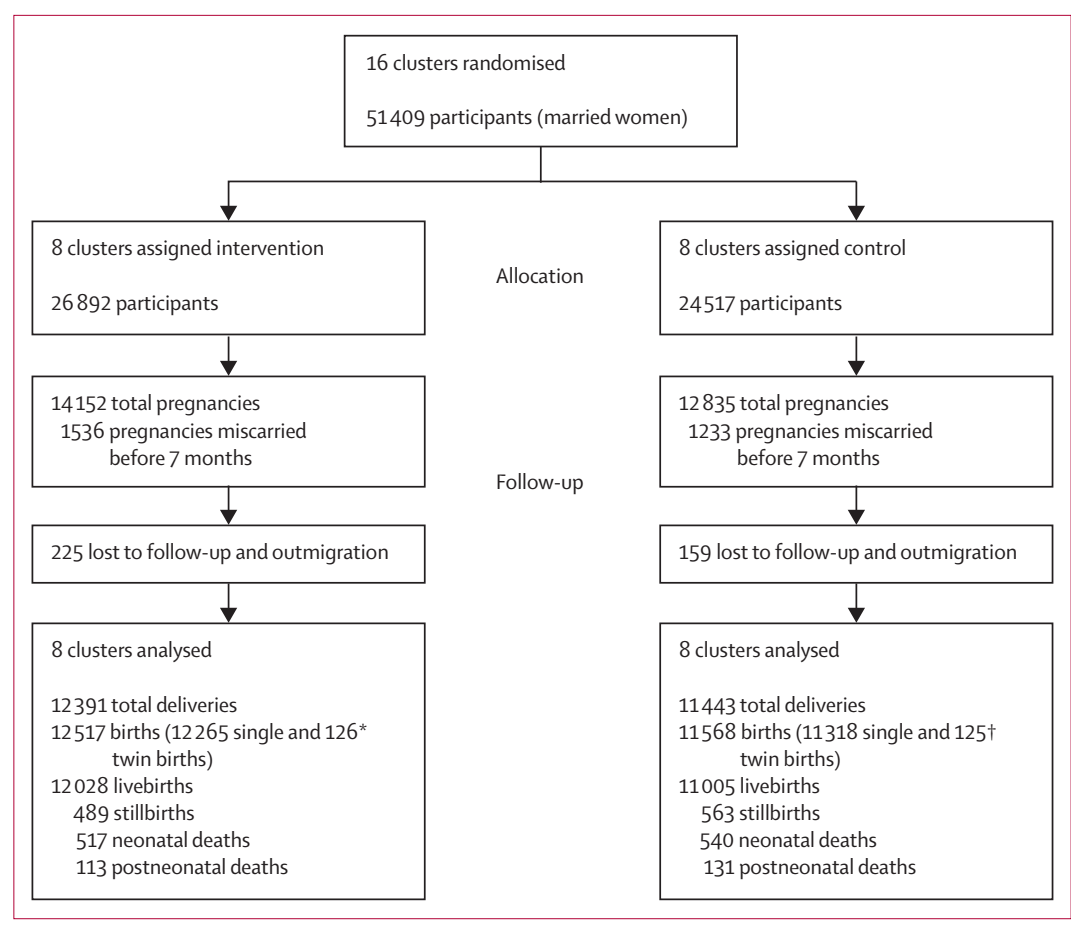

Figure 2: Trial profile

*Pairs of twins included: 109 both livebirths, five both stillbirths, and 12 one livebirth and one stillbirth. †Pairs of twins included: 115 both livebirths, two both stillbirths, and eight one livebirth and one stillbirth.

\begin{tabular}{|c|c|c|}
\hline & $\begin{array}{l}\text { Intervention } \\
\text { (8 clusters) }\end{array}$ & $\begin{array}{l}\text { Control } \\
8 \text { clusters) }\end{array}$ \\
\hline Total population & 158393 & 159833 \\
\hline Households & 23353 & 23768 \\
\hline Mean number of people per household & $6 \cdot 8(3 \cdot 4)$ & $6.7(3 \cdot 4)$ \\
\hline Mean number of children younger than 5 years per household & $1 \cdot 3(1 \cdot 3)$ & $1 \cdot 2(1 \cdot 3)$ \\
\hline \multicolumn{3}{|l|}{ Maternal education* } \\
\hline Illiterate & $19674(83 \%)$ & $18776(80 \%)$ \\
\hline Able to read and write & $1117(5 \%)$ & $893(4 \%)$ \\
\hline Primary and middle school & $1877(8 \%)$ & $2318(10 \%)$ \\
\hline Higher secondary school & $789(3 \%)$ & $1123(5 \%)$ \\
\hline Graduate and above & $160(1 \%)$ & $374(2 \%)$ \\
\hline Not reported & $98(<1 \%)$ & $40(<1 \%)$ \\
\hline Mean total household monthly earnings (US\$) & $97 \cdot 6(126 \cdot 0)$ & $101 \cdot 9(125 \cdot 6)$ \\
\hline Families owning their own home & $18583(80 \%)$ & $18664(79 \%)$ \\
\hline Single-room households & $15994(68 \%)$ & $15406(65 \%)$ \\
\hline Households with no toilet facility & $14091(60 \%)$ & $12184(51 \%)$ \\
\hline Households with piped water or a hand pump & $15537(67 \%)$ & $14126(59 \%)$ \\
\hline Households using firewood for cooking & $21113(90 \%)$ & $19613(83 \%)$ \\
\hline Households with electricity & $17624(75 \%)$ & $19232(81 \%)$ \\
\hline \multicolumn{3}{|c|}{ Data are $n, n(\%)$, or mean (SD). ${ }^{*} n=47239$ (23715 in intervention clusters, 23524 in control). } \\
\hline
\end{tabular}

Data collectors and their supervisors were masked to cluster allocation. Anthropologists undertaking verbal and social autopsies were masked to cluster allocation and nature of training of LHWs in their area. Data analysts were not masked to the cluster allocation.

\section{Procedures}

We established 13 independent data collection teams who undertook quarterly visits to all villages in intervention and control clusters. The household surveillance system was designed on the basis of geographic boundaries and contiguity of villages, rather than clusters. Data were obtained from each household for all births, deaths, inmigrations, and outmigrations. From the second surveillance round onwards, women reporting livebirths in the 4 weeks preceding the visit were interviewed with a structured questionnaire to obtain information about knowledge and practices relating to newborn care and LHW visits. Additionally, LHWs in the intervention clusters were asked to record information about home visits, newborn illnesses, referrals, and deaths on special proformas. A separate team obtained data for births, newborn referrals, and outcomes from the registers of public and private sector health facilities in the area. Verbal and social autopsies of stillbirths and neonatal deaths were done by a separate team of trained anthropologists within 12-16 weeks of the event. The verbal autopsy instruments used for obtaining information about stillbirths and newborn deaths were based on adaptations of WHO recommended instruments used for assessing neonatal deaths and stillbirths. ${ }^{21-23}$ The primary outcome of the trial was perinatal and all-cause neonatal mortality.

\section{Statistical analysis}

After the pilot phase, a complete household and health facility survey was done between May and August, 2005 in the 16 clusters selected for the full trial, to measure socioeconomic characteristics and document baseline perinatal and neonatal mortality rates on the basis of recall of all births and deaths in the preceding year. Using data from the baseline census and the method described by Hayes and Bennett, ${ }^{24}$ we estimated the coefficient of variation in NMRs between clusters to be $0 \cdot 16$. With this estimate of the coefficient, and assuming that during a 2 -year period there would be an average of 1400 livebirths per cluster, we estimated that we would have close to $90 \%$ power to detect a $30 \%$ reduction in NMR from 50 deaths per 1000 livebirths to 35 deaths per 1000 livebirths. ${ }^{5}$ The power to detect a reduction of $25 \%$ was close to $75 \%$.

Since the number of randomised clusters was small we chose to analyse the primary outcome data (perinatal and neonatal mortality) at cluster level as recommended by Hayes and Moulton, ${ }^{25}$ and to adjust for baseline (preintervention) mortality rates. Analysis was by intention to treat. For each cluster, the NMR during the intervention phase was calculated and the logarithm of the cluster-level NMRs was then used as the independent variable in a linear regression model to provide an estimate of the NMR ratio associated with the intervention and its $95 \% \mathrm{CI}$, while accounting for the cluster randomisation. Stratum was included as a fixed effect in the model. The logarithm 
of the baseline (preintervention) cluster-level NMR was included as a covariate and the regression was weighted on the basis of the number of events in each cluster. A similar approach was used to analyse stillbirth rates. All analyses were done with Stata (version 10). When analysing reported practices before, during, and after delivery, we used the svy commands within Stata to account for the clustered nature of the data. No interim analyses of mortality were done.

The Hala trial is registered, ISRCTN16247511

\section{Role of the funding source}

The funding bodies provided clearance for the project design, but apart from field visits to review progress, did not influence the field trial or the data analysis procedures. The corresponding author had full access to all the data in the study and had final responsibility for the decision to submit for publication.

\section{Results}

Figure 2 shows the trial profile and outcomes for all 16 clusters. Table 2 shows baseline household characteristics. Most mothers (>80\%) were illiterate and although most families owned their own house, less than half had access to a toilet and most used firewood for cooking. In 38 villages (17 in intervention and 21 in control clusters), there were pre-existing committees principally focused on initiatives facilitating education. These committees were at various levels of functionality and none were undertaking activities related to maternal and newborn care. The overall population covered by the LHW programme in the study area at baseline was 77\%, and the number of resident LHWs per 10000 population was similar in intervention and control clusters (table 3). Baseline stillbirth and neonatal mortality rates were slightly lower in the intervention group than in the control group (table 3; webappendix pp 3-4). Roughly $40 \%$ of all births occurred in local facilities (both public and private), with the remainder of births at home (table 3 ).

$488(96 \%)$ of 506 villages in the intervention clusters established CHCs during the study, of whom 249 (51\%) also established emergency transport funds. Most CHCs met at least quarterly and had regular liaisons with the LHW. No new LHWs were recruited during the study, and apart from two increments in salaries, in 2006 and 2009, no significant changes were introduced in the main curriculum and training programme for LHWs.

LHWs in the intervention areas were able to undertake 4428 (63\%) of 7084 planned quarterly community group sessions in villages and self-reported visiting and examining 2943 neonates (24\%) of a total 12028 livebirths in the intervention clusters (1213 and 1730 in years 1 and 2 of the study, respectively), but none were able to implement all four suggested postnatal home visits. LHWs in the intervention clusters also reported examining 248 unwell neonates (42 in year 1 and 206 in year 2). Of these, 72 (29\%) babies with suspected severe

\begin{tabular}{|c|c|c|}
\hline & $\begin{array}{l}\text { Intervention } \\
\text { (8 clusters) }\end{array}$ & $\begin{array}{l}\text { Control } \\
\text { (8 clusters) }\end{array}$ \\
\hline Population & 158393 & 159833 \\
\hline LHWs in post & 134 & 154 \\
\hline Resident LHWs & 122 & 120 \\
\hline Resident LHWs per 10000 population & $7 \cdot 2$ & $7 \cdot 5$ \\
\hline \multicolumn{3}{|c|}{ Events reported in past 12 months (from baseline household survey) } \\
\hline Miscarriages identified & 477 & 432 \\
\hline All births identified & 5797 & 5620 \\
\hline Livebirths identified & 5585 & 5385 \\
\hline \multicolumn{3}{|l|}{ Stillbirths } \\
\hline Number & 212 & 235 \\
\hline Rate per 1000 total births & $36 \cdot 6$ & $41 \cdot 8$ \\
\hline \multicolumn{3}{|l|}{ Perinatal mortality } \\
\hline Number & 393 & 405 \\
\hline Rate per 1000 total births & $67 \cdot 8$ & $72 \cdot 1$ \\
\hline \multicolumn{3}{|l|}{ Neonatal mortality } \\
\hline Number & 268 & 276 \\
\hline Rate per 1000 livebirths & $48 \cdot 0$ & $51 \cdot 3$ \\
\hline Facility births & $2279(41 \%)$ & $2342(44 \%)$ \\
\hline \multicolumn{3}{|l|}{ LHW=lady health worker. } \\
\hline $\begin{array}{l}\text { Table 3: Baseline LHW coverage and o } \\
\text { previous year }\end{array}$ & omes of preg & ncies in the \\
\hline
\end{tabular}

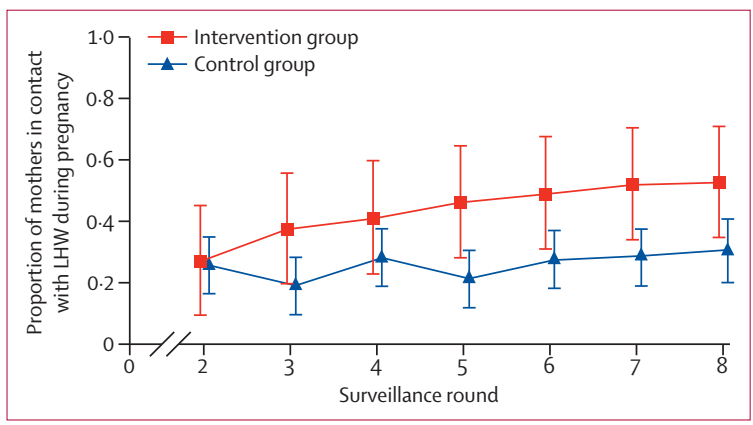

Figure 3: Reported home visits of LHWs during pregnancy Error bars show $95 \% \mathrm{Cls}$. LHW=lady health worker.

illnesses were referred to health facilities or local physicians, and others with non-severe problems were managed at home. There were no reported deaths in this subgroup. The independent household surveillance documented 651 home visits by LHWs in the intervention clusters compared with 212 in control clusters. There was a trend of increasing home visits by LHWs during pregnancy reported by women in the intervention clusters during the trial $(\mathrm{p}<0 \cdot 0001$; figure 3$)$.

During the last 6 months of the intervention, 346 (52\%) of 661 pregnant women in the intervention clusters reported being visited by an LHW compared with 198 (30\%) of 658 in the control group. Furthermore, by this stage of the intervention, 423 (67\%) of 661 pregnant women in the intervention clusters had attended a group session run by LHWs. In the second year of the intervention, $40 \%$ of group sessions in the intervention clusters were attended 
by additional family members and at a quarter of the sessions, some husbands also attended.

The major pregnancy outcomes (miscarriages, stillbirths, neonatal deaths, and livebirths) were determined through self-reporting in the quarterly household surveillance system. The baseline rates of miscarriage were similar in both groups (76 reported miscarriages per 1000 pregnancies in intervention clusters vs 71 in control clusters). Subsequently, during the intervention period, reported miscarriage rates were higher in both

\begin{tabular}{|c|c|c|c|c|}
\hline & $\begin{array}{l}\text { Intervention } \\
\text { clusters }\end{array}$ & $\begin{array}{l}\text { Control } \\
\text { clusters }\end{array}$ & $\begin{array}{l}\text { Mortality risk } \\
\text { ratio }(95 \% \mathrm{Cl})^{*}\end{array}$ & p value \\
\hline Livebirths identified & 12028 & 11005 & .. & .. \\
\hline Postneonatal infant deaths $\dagger$ & 113 & 131 &.. & .. \\
\hline \multicolumn{5}{|l|}{ Miscarriages } \\
\hline Number & 1536 & 1233 & .. & .. \\
\hline Rate per 1000 known pregnancies & 109 & 96 & $1.12(0.89-1.40)$ & $0 \cdot 31$ \\
\hline \multicolumn{5}{|l|}{ Stillbirths } \\
\hline Number & 489 & 563 & .. & .. \\
\hline Rate per 1000 total births & $39 \cdot 1$ & $48 \cdot 7$ & $0.79(0.68-0.92)$ & 0.006 \\
\hline \multicolumn{5}{|l|}{ Early neonatal mortality $\dagger$} \\
\hline Number & 391 & 409 & .. & .. \\
\hline Rate per 1000 livebirths & $32 \cdot 5$ & $37 \cdot 2$ & $0.86(0.75-0.98)$ & 0.03 \\
\hline \multicolumn{5}{|l|}{ Late neonatal mortality $\dagger$} \\
\hline Number & 126 & 131 & .. & .. \\
\hline Rate per 1000 livebirths & $10 \cdot 5$ & $11 \cdot 9$ & $0.83(0.64-1.07)$ & 0.13 \\
\hline \multicolumn{5}{|l|}{ Neonatal mortality $\dagger$} \\
\hline Number & 517 & 540 & .. & .. \\
\hline Rate per 1000 livebirths & $43 \cdot 0$ & $49 \cdot 1$ & $0.85(0.76-0.96)$ & 0.02 \\
\hline \multicolumn{5}{|l|}{ Perinatal mortality } \\
\hline Number & 880 & 972 & .. & .. \\
\hline Rate per 1000 total births & $70 \cdot 3$ & $84 \cdot 0$ & $0.83(0.74-0.93)$ & 0.004 \\
\hline \multicolumn{5}{|c|}{$\begin{array}{l}\text { *All parameter estimates, } \mathrm{Cl} \text {, and p values estimated by (weighted) analysis of variance at the cluster level; depender } \\
\text { variable=log (rate); stratification used in the randomisation included as a fixed effect; log (baseline neonatal mortalit } \\
\text { rate) included as a covariate; weights used were based on the number of events reported in each cluster. †Neonatal } \\
\text { defined as age 0-28 days; postneonatal, 29-365 days; early neonatal, 0-7 days; and late neonatal, 8-28. }\end{array}$} \\
\hline
\end{tabular}

groups, particularly in the intervention clusters (109 reported miscarriages per 1000 pregnancies in intervention clusters vs 96 in control clusters; risk ratio [RR] 1.12, 95\% CI 0.89-1.40; $\mathrm{p}=0 \cdot 31$ ). No clear time trend for miscarriages was discernible. Rates of stillbirth (RR $0.79,0.68-0.92 ; \mathrm{p}=0.006$ ) and neonatal mortality (RR $0.85,0.76-0.96 ; \mathrm{p}=0.02$ ) were significantly lower in intervention clusters than control (table 4). Stillbirth rates in the intervention clusters seemed to decrease with time, while remaining roughly constant in the control clusters (webappendix pp 5-6). Within the intervention clusters, neonatal mortality seemed lower in the areas covered by LHWs ( 37.6 per 1000 livebirths) than in areas that were not covered (48.3 deaths per 1000 livebirths), whereas no major difference was apparent in the control clusters (47.8 vs 50.4 per 1000 livebirths, respectively; test for interaction $\mathrm{p}=0 \cdot 04$ ). There were seven fewer maternal deaths in the intervention clusters than in the control clusters (71 vs 78) during the study.

Information about household practices was available for 4474 pregnancies resulting in a livebirth, representing $19 \%$ of all 23033 livebirths during that period and $58 \%$ of all livebirths in the 28 days preceding the surveillance visit (table 5). The most common reason for lack of access to women who had delivered in the past 28 days was the common cultural practice of women delivering in their parents' house and residing with them for 40 days after childbirth. The ratio of women with recent deliveries (within 28 days) who were surveyed was similar in intervention (2339 [19\%] of 12028 livebirths) and control (2135 [19\%] of 11005 livebirths) clusters.

More women in the intervention clusters than control reported attendance for antenatal care in facilities (table 5 ; figure 4), but this difference was small and not significant and could reflect sampling variation. However, women in intervention clusters reported significantly more frequent contact with their LHW during pregnancy than did those in the control clusters ( $44 \%$ vs $26 \%$; $p=0.05$ ). Among women delivering at home, the use of clean delivery kits

\begin{tabular}{|c|c|c|c|c|c|}
\hline & \multicolumn{2}{|c|}{ Intervention group $(\mathrm{n}=2339)$} & \multicolumn{2}{|c|}{ Control group $(n=2135)$} & \multirow[t]{2}{*}{ p value } \\
\hline & $\mathrm{n} / \mathrm{N}$ & $\%(95 \% \mathrm{Cl})$ & $\mathrm{n} / \mathrm{N}$ & $\%(95 \% \mathrm{Cl})$ & \\
\hline Women attending at least one antenatal consultation in a facility & $1616 / 2339$ & $69 \%(56-82)$ & $1230 / 2135$ & $58 \%(39-76)$ & 0.29 \\
\hline Women attending four or more antenatal consultations in a facility & $302 / 2339$ & $13 \%(9-17)$ & $191 / 2135$ & $9 \%(2-16)$ & 0.36 \\
\hline Women having contact with LHW during pregnancy & $1019 / 2334$ & $44 \%(31-56)$ & $553 / 2123$ & $26 \%(15-37)$ & 0.05 \\
\hline Women delivering in a facility & $1272 / 2339$ & $54 \%(48-61)$ & $936 / 2135$ & $44 \%(34-53)$ & 0.07 \\
\hline Home deliveries using a clean delivery kit & $302 / 867$ & $35 \%(27-43)$ & $34 / 1102$ & $3 \%(2-5)$ & $<0.0001$ \\
\hline Mothers giving colostrum & $1828 / 2311$ & $79 \%(75-83)$ & $1218 / 2109$ & $58 \%(51-64)$ & $<0.0001$ \\
\hline Mothers initiating breastfeeding within $30 \mathrm{~min}$ & $989 / 2326$ & $43 \%(33-52)$ & $583 / 2122$ & $27 \%(19-36)$ & 0.03 \\
\hline Mothers delaying bathing until after $6 \mathrm{~h}$ & $1142 / 2294$ & $50 \%(39-60)$ & $580 / 2117$ & $27 \%(17-38)$ & 0.008 \\
\hline Mothers visited by LHW within 3 days of delivery & $792 / 2326$ & $34 \%(19-48)$ & $278 / 2129$ & $13 \%(6-20)$ & 0.005 \\
\hline LHW=lady health worker. & & & & & \\
\hline
\end{tabular}




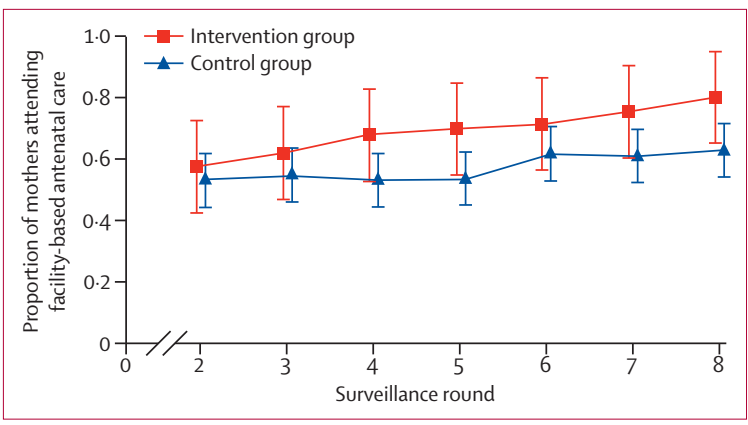

Figure 4: Trends in facility-based antenatal care

Facility-based antenatal care defined as one visit, to any provider. Error bars show $95 \% \mathrm{Cls}$.

was much more common in the intervention clusters (35\% vs 3\%; $<<0 \cdot 0001)$.

During the study overall, women in the intervention clusters were more likely but not significantly to report delivering in a facility (54\% vs $44 \%$; $\mathrm{p}=0 \cdot 07$; table 5 ). However, there was clear evidence of an increasing trend towards facility delivery over time in the intervention clusters, whereas there was little or no such trend in the control clusters (test for difference in trends, $\mathrm{p}=0 \cdot 002$;

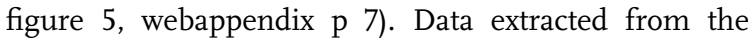
registers of the main public sector hospitals, which accounted for almost $55 \%$ of public sector facility births in the district between 2005 and 2007, show a 35\% increase in the number of deliveries $(n=9472)$ compared with the previous 2 years (2003-2005).

Analysis of surveillance data identified important differences in newborn care practices between the two groups. Women in intervention clusters were more likely than were women in control clusters to report giving colostrum (79\% vs $58 \%$; $\mathrm{p}<0 \cdot 0001)$, breastfeeding within 30 min after birth (43\% vs 27\%; $\mathrm{p}=0.03)$, delaying bathing beyond $6 \mathrm{~h}$ ( $50 \%$ vs 27\%; $\mathrm{p}=0.008)$, and receiving a postnatal visit from the LHW within 3 days of delivery (23\% vs $8 \%$; $\mathrm{p}=0.005$ ) (table 5).

There were no major differences in the prevalence of illnesses in neonates and careseeking patterns between the two groups. The surveillance team documented 2193 unwell neonates in intervention clusters compared with 2018 in control clusters. Of these, 1859 (85\%) in the intervention clusters and 1510 (75\%) in the control clusters had sought care outside the home, usually from private sector physicians (1514 [81\%] in intervention and 1408 [93\%] in the control clusters). Few reported seeking care from the LHW for a suspected newborn illness beyond the first week of age (data not shown). These data are consistent with recorded information about neonatal referrals to the local public sector health facilities. 1615 newborn infants were presented to the local public sector outpatient or emergency facilities for care during the study, of which most (ie, 1579) were self-referred and only 46 had a documented referral from an LHW.

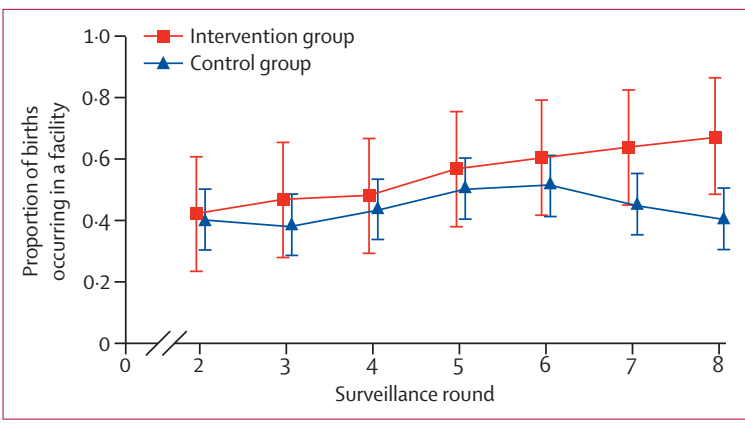

Figure 5: Trends in facility births

Error bars show $95 \% \mathrm{Cls}$.

\section{Discussion}

Despite low coverage and high complexity, the intervention was associated with significant reductions in stillbirths and neonatal mortality in this rural district of Pakistan (panel 2). As in the pilot phase, ${ }^{16}$ key household behaviours for maternal and early newborn care improved, with evidence of improving trends over time for some indicators. The biggest changes occurred in behaviours related to seeking of antenatal care and in-facility births. By contrast, no important differences were seen in referral or careseeking patterns for newborn babies.

Some limitations should be noted. Our surveillance system did not use prospective pregnancy tracking owing to the large population size and concerns about the Hawthorne effect of repeated home visits for data collection. Because of the size of the study area, 13 independent data collection teams were charged with regular surveillance, and complete masking of cluster allocation was not feasible. However, strict systems of monitoring, data quality assurance, and random checks were in place and the data collectors covered sequential villages irrespective of cluster allocation.

In view of the geographical boundaries, the issue of contamination and diffusion between intervention and control clusters should be considered. There were no transfers or migrations of LHWs between intervention and control villages during the trial and training sessions were done within the clusters. However, we cannot exclude the possibility of exchange or diffusion of information between intervention and control villages through $\mathrm{CHC}$ members and participants in the group sessions.

Our data for household practices are based on mothers' verbal reports of what they did, rather than observed behaviours. Over-reporting of recommended practices in the intervention clusters cannot be excluded. Nor can we discount the possibility of improved reporting by mothers of early fetal losses and pregnancy outcomes in the intervention clusters. Furthermore, we cannot entirely exclude the possibility of differential misclassification of miscarriages and stillbirths between the intervention and control clusters, despite full masking of teams undertaking verbal and social autopsies. We found no systematic differences between intervention and control clusters in 
Panel 2: Research in context

\section{Systematic review}

Growing evidence exists of the effectiveness of various approaches to community-based delivery strategies and platforms to address neonatal mortality and morbidity. We have documented that various community-based interventions work and have the potential to reduce neonatal mortality. ${ }^{10,26}$ Similarly Lewin and colleagues ${ }^{27}$ have shown the benefits of using lay health workers or traditional birth attendants in improving a range of child health outcomes, and Sibley and co-worker ${ }^{28}$ have made the case for training of traditional birth attendants to reduce perinatal mortality. We have also shown that community support groups using health workers or other community mobilisers could affect household behaviours and improve newborn outcomes and careseeking ${ }^{19}$ Others ${ }^{11}$ have evaluated the effect of home visits on neonatal mortality and shown significant benefits. However, few studies have evaluated packages of care and none have done so in effectiveness settings.

\section{Interpretation}

The results of our study suggest that trained public sector community health workers in rural Pakistan can deliver a package of preventive and promotive health care messages to community members. Despite limitations of time and competing tasks, lady health workers (LHWs) were able to build a rapport with community members and implement a package of promotive and preventive maternal and newborn care interventions. Although the overall coverage achieved by the LHW-supported intervention was low, the effect on crucial household behaviours and careseeking patterns was promising. The LHWs were also able to liaise with local traditional birth attendants (Dais) and volunteer community health committees, and provide community education and advocacy for facility births. These findings add to the growing evidence base for the efficacy and effectiveness of community-based approaches to address newborn mortality in difficult-to-reach areas and support use of strategies involving outreach workers in such settings.

the classification of fetal deaths as miscarriages or stillbirths, nor in classification of stillbirths as very early neonatal deaths or vice versa. However, current methods of verbal autopsies are at best fairly crude in differentiation of late miscarriages, stillbirths, and early neonatal deaths, and misclassification cannot be entirely excluded. . $^{293}$

The reductions in stillbirths and neonatal deaths were smaller than the $34 \%$ and $28 \%$ reductions reported in the pilot phase, ${ }^{16}$ and were lower than those reported from other recent large cluster randomised trials in south Asia. ${ }^{12-15}$ The scale-up phase of the Hala effectiveness trial was three times larger than the initial pilot and was much bigger than other studies in the region. It also differed from other studies in the region ${ }^{12-15,17,18}$ in that the intervention was principally delivered through the government health system rather than by workers employed directly by the research team. Referral health facilities serving both intervention and control clusters were strengthened and the population in the control clusters received basic maternal and newborn care through the existing LHW programme.

Other contextual factors should be considered. The intervention was complex and was delivered through public sector LHWs and the government health system, and was thus subject to human resource constraints, the competing demands of other routine activities, and general weaknesses in health system functionality. These factors affect LHW job stress and performance. ${ }^{9,31}$ The investigators had little control over local managers, several of whom were transferred into and out of the district several times. Even the robust federal LHW programme saw three changes of leadership at the federal and four at the provincial level between 2004 and 2008. Although the changes did not prevent the introduction of the project in the district, several agreed actions by the Directorate of Health, such as deployment of additional LHWs to cover the entire area, replacement of LHWs who were not locally based, and provision of key commodities such as newborn weighing scales, were not implemented. Almost a quarter of the target population and villages of the area remained uncovered by LHWs, who in turn often had to multitask and provide logistical support to other government programmes, as per policy. From work registers we estimate that during the course of the intervention, study LHWs spent an average $30 \%$ of their time on the periodic polio eradication campaigns, which interrupted regular maternal, neonatal, and child health activities. The fairly low coverage of the intervention overall should therefore be seen in the context of a busy functional primary care $\mathrm{CHW}$ programme being charged with implementing a complex package of community-based advocacy and education.

Despite these limitations and the known reduction in effectiveness when scaling up from efficacy trials, ${ }^{32}$ the Hala trial provides encouragement that a public sector programme promoting preventive maternal and newborn care can lead to behavioural change and careseeking for mothers during pregnancy and childbirth with resultant health benefits. The observed reduction in stillbirths paralleled the increase in facility births and skilled attendance during delivery in the intervention clusters. The two main public sector hospitals in the district already had trained obstetricians and midwives with adequate facilities for emergency obstetric care.

We are unable to ascribe improvements in perinatal and neonatal outcomes to any single component of the three elements of the intervention package. The LHWs played a key part in the implementation of all three components, although overall coverage rates of various components of the intervention package varied. The LHWs were able to liaise with CHCs and deliver the community group sessions with greater efficiency than targeted postnatal home visits and overall coverage of some components of LHW supported activities, such as presence during childbirth, immediate postnatal visits, and examination of sick neonates, remained low. We speculate therefore that the pathway for effectiveness of the Hala intervention was largely through improved antenatal contact with LHWs leading to improved childbirth care for mothers, including increased facility births in the hands of skilled attendants, and improvements in some elements of immediate newborn care. ${ }^{33}$

The lack of improvement in careseeking for newborn illnesses in the intervention clusters could be related to 
the poor quality of care for newborns in the local public sector facilities and the reluctance among families to travel long distances to seek newborn care., ${ }^{5,34}$ The information available about the subset of newborn infants with illnesses also suggested that careseeking was largely in the formal and informal private sector.

Urgent attention is needed for the provision of adequate basic and emergency newborn care facilities in the health system, and the LHW programme might also consider inclusion of interventions for immediate newborn care such as emergency resuscitation, kangaroo mother care, and oral antibiotic treatment for suspected respiratory infections. By contrast with others, ${ }^{12,13}$ we did not provide any home-based bag and mask resuscitation or antibiotic treatment. Despite indications that these interventions are efficacious, further trials are needed in effectiveness settings, especially those that integrate intervention packages across the continuum of care..$^{35}$ Recent systematic reviews of community health workers suggest that they are effective in delivering a range of interventions to affect newborn health and child survival. ${ }^{27,36,37}$ Such programmatic interventions and implementation research are a priority.

Previous projections have suggested that community and outreach interventions, if implemented at scale, have the potential of reducing newborn deaths by $36 \% .{ }^{26}$ Despite much lower coverage in our trial than in other efficacy trials, the intervention package was associated with a reduction in perinatal and newborn mortality of 15-20\%. More importantly, we found that LHWs could work effectively with existing Dais in the area. Since training of traditional birth attendants has little effect on reducing perinatal mortality, ${ }^{28}$ these findings suggest a way to link various public and private sector health workers in health systems with promotion of skilled care and in-facility births for families. Future strategies could combine CHW-based programmes with additional modalities for promotion of facility births through community education, ${ }^{34}$ public-private partnerships, ${ }^{38}$ and fiscal incentive schemes. ${ }^{39}$ However, to be effective, such health workers and programmes need close oversight and dedicated activities.

\section{Contributors}

$\mathrm{ZAB}$ drew up the project proposal and was the principal investigator for the Hala trial. ZAB also wrote the first draft of the manuscript with contributions from SS and SC. SC, AF, and IA undertook the statistical analyses. All authors contributed to the implementation, data review, and writing process.

\section{Conflicts of interest}

We declare that we have no conflicts of interest.

\section{Acknowledgments}

The Hala trial was funded by grants from WHO and the Saving Newborn Lives programme funded by the Bill \& Melinda Gates Foundation. We thank Department of Health, Sindh Government, and the National Program for Family Planning and Primary Health Care for their encouragement and support towards undertaking this trial, all staff of the Hala project office for their hard work and support, and notably, the excellent support provided by Usman Chachar, the district coordinating officer, and Hasan Murad Shah, the executive district officer for health for Matiari district.

\section{References}

1 Rajaratnam JK, Marcus JR, Flaxman AD, et al. Neonatal, postneonatal, childhood, and under-5 mortality for 187 countries, 1970-2010: a systematic analysis of progress towards Millennium Development Goal 4. Lancet 2010; 375: 1988-2008.

2 Lawn JE, Cousens S, Zupan J, for the Lancet Neonatal Survival Steering Team. 4 million neonatal deaths: When? Where? Why? Lancet 2005; 365: 891-900.

3 Bhutta ZA, Cross A, Raza F, Zaheer Z. Chapter 8. Infant and child mortality. In: Pakistan demographic and health survey 2006-07. Islamabad, Pakistan: National Institute of Population Studies, Pakistan, and Macro International Inc, 2008.

4 Jafarey SN. Characteristics and practices of traditional birth attendants (Dais) a preliminary survey. J Pak Med Assoc 1981; 31: 288-91.

5 Bhutta ZA, Ali N, Hyder AA, Wajid A. Perinatal and newborn care in Pakistan: seeing the unseen. In: Bhutta ZA, ed. Maternal and child health in Pakistan: challenges and opportunities. Karachi, Pakistan: Oxford University Press, 2004.

6 National Programme for Family Planning and Primary Health Care. Ministry of Health, Government of Pakistan. http://www.phc.gov.pk (accessed May 2, 2010).

7 Douthwaite M, Ward P. Increasing contraceptive use in rural Pakistan: an evaluation of the Lady Health Worker Programme. Health Policy Plan 2005; 20: 117-23.

8 Oxford Policy Management. Evaluation of the Prime Minister's Lady Health Worker Programme. 2003. http://www.opml.co.uk/ policy_areas/statistics/quantitative_information_for_policy_and_ programme/cn1064_lhw.html (accessed Dec 23, 2010).

9 Oxford Policy Management. External evaluation of the Lady Health Worker Programme, Pakistan. 2009. http://www.opml.co.uk/ policy_areas/statistics/quantitative_information_for_policy_and_ programme/6241_lhw.html (accessed Dec 23, 2010).

10 Bhutta ZA, Darmstadt GL, Hasan BS, Haws RA. Community-based interventions for improving perinatal and neonatal health outcomes in developing countries: a review of the evidence. Pediatrics 2005; 115 (2 suppl): 519-617.

11 Gogia S, Sachdev HPS. Home visits by community health workers to prevent neonatal deaths in developing countries: a systematic review. Bull World Health Organ 2010; 88: 658-66.

12 Bang AT, Bang RA, Baitule SB, Reddy MH, Deshmukh MD. Effect of home-based neonatal care and management of sepsis on neonatal mortality: field trial in rural India. Lancet 1999; 354: 1955-61.

13 Baqui AH, El-Arifeen S, Darmstadt GL, et al, for the Projahnmo Study Group. Effect of community-based newborn-care intervention package implemented through two service-delivery strategies in Sylhet district, Bangladesh: a cluster-randomised controlled trial. Lancet 2008; 371: 1936-44.

14 Manandhar DS, Osrin D, Shrestha BP, et al, and members of the MIRA Makwanpur trial team. Effect of a participatory intervention with women's groups on birth outcomes in Nepal: cluster-randomised controlled trial. Lancet 2004; 364: 970-79.

15 Tripathy P, Nair N, Barnett S, et al. Effect of a participatory intervention with women's groups on birth outcomes and maternal depression in Jharkhand and Orissa, India: a cluster-randomised controlled trial. Lancet 2010; 375: 1182-92.

16 Bhutta ZA, Memon ZA, Soofi S, Salat MS, Cousens S, Martines J. Implementing community-based perinatal care: results from a pilot study in rural Pakistan. Bull World Health Organ 2008; 86: 452-59.

17 Baqui AH, Rosecrans AM, Williams EK, et al. NGO facilitation of a government community-based maternal and neonatal health programme in rural India: improvements in equity. Health Policy Plan 2008; 23: 234-43.

18 Kumar V, Mohanty S, Kumar A, et al, for the Saksham Study Group. Effect of community-based behaviour change management on neonatal mortality in Shivgarh, Uttar Pradesh, India: a cluster-randomised controlled trial. Lancet 2008; 372: 1151-62.

19 Bhutta ZA, Lassi ZS. Empowering communities for maternal and newborn health. Lancet 2010; 375: 1142-44.

20 Hayes RJ, Moulton LH. Cluster randomised trials. London, UK: Chapman and Hall/CRC Interdisciplinary Statistics, 2008.

21 WHO. Standard neonatal verbal autopsy questionnaire, revised version: WHO/JHU/SNL. Geneva, Swizerland: World Health Organization, 2003. 
22 Baqui AH, Darmstadt GL, Williams EK, et al. Rates, timing and causes of neonatal deaths in rural India: implications for neonata health programmes. Bull World Health Organ 2006; 84: 706-13.

23 Kalter HD, Khazen RR, Barghouthi M, Odeh M. Prospective community-based cluster census and case control study of stillbirths and neonatal deaths in the West Bank and Gaza Strip. Paediatr Perinat Epidemiol 2008; 22: 321-33.

24 Hayes RJ, Bennett S. Simple sample size calculation for cluster-randomized trials. Int J Epidemiol 1999; 28: 319-26.

25 Moulton LH. Covariate-based constrained randomization of group-randomized trials. Clin Trials 2004; 1: 297-305.

26 Darmstadt GL, Bhutta ZA, Cousens S, Adam T, Walker N, de Bernis L, for the Lancet Neonatal Survival Steering Team. Evidence-based, cost-effective interventions: how many newborn babies can we save? Lancet 2005; 365: 977-88.

27 Lewin S, Munabi-Babigumira S, Glenton C, et al. Lay health workers in primary and community health care for maternal and child health and the management of infectious diseases. Cochrane Database Syst Rev 2010; 3: CD004015.

28 Sibley LM, Sipe TA, Brown CM, Diallo MM, McNatt K, Habarta N. Traditional birth attendant training for improving health behaviours and pregnancy outcomes. Cochrane Database Syst Rev 2007; 3: CD005460.

29 Edmond KM, Quigley MA, Zandoh C, et al. Diagnostic accuracy of verbal autopsies in ascertaining the causes of stillbirths and neonatal deaths in rural Ghana. Paediatr Perinat Epidemiol 2008; 22: 417-29.

30 Carlo WA, Goudar SS, Jehan I, et al, for the First Breath Study Group. Newborn-care training and perinatal mortality in developing countries. N Engl J Med 2010; 362: 614-23.

31 Haq Z, Iqbal Z, Rahman A. Job stress among community health workers: a multi-method study from Pakistan. Int J Ment Health Syst 2008; 2: 15.
32 Tugwell P, de Savigny D, Hawker G, Robinson V. Applying clinical epidemiological methods to health equity: the equity effectiveness loop. BMJ 2006; 332: 358-61.

33 Baqui AH, Ahmed S, El Arifeen S, et al, for the Projahnmo 1 Study Group. Effect of timing of first postnatal care home visit on neonatal mortality in Bangladesh: a observational cohort study. BMJ 2009; 339: b2826.

34 Midhet F, Becker S. Impact of community-based interventions on maternal and neonatal health indicators: Results from a community randomized trial in rural Balochistan, Pakistan. Reprod Health 2010; 7: 30 .

35 Bhutta ZA, Chopra M, Axelson H, et al. Countdown to 2015 decade report (2000-10): taking stock of maternal, newborn, and child survival. Lancet 2010; 375: 2032-44.

36 Bhutta ZA, Lassi ZS, Pariyo G, Huicho L. Global experience of community health workers for delivery of health related Millennium Development Goals: a systematic review, country case studies, and recommendations for scaling up. Geneva, Switzerland: Global Health Workforce Alliance, 2010. http://www.who.int/ workforcealliance/knowledge/publications/CHW_FullReport_2010. pdf (accessed Dec 23, 2010).

37 Lassi Z, Haider B, Bhutta ZA. Community-based intervention packages for preventing maternal morbidity and mortality and improving neonatal outcomes. New Delhi, India: International Initiative for Impact Evaluation, 2010.

38 Lim SS, Dandona L, Hoisington JA, James SL, Hogan MC, Gakidou E. India's Janani Suraksha Yojana, a conditional cash transfer programme to increase births in health facilities: an impact evaluation. Lancet 2010; 375: 2009-23.

39 Mavalankar D, Singh A, Patel SR, Desai A, Singh PV. Saving mothers and newborns through an innovative partnership with private sector obstetricians: Chiranjeevi scheme of Gujarat, India. Int J Gynaecol Obstet 2009; 107: 271-76. 